\title{
Measurement of Effective Vapor Temperature in Graphite Furnace of Atomic Absorption Spectrometry
}

\author{
Yasushi TerUI*, Kazuo YASUdA** and Kichinosuke HiroKawA* \\ * Institute for Materials Research, Tohoku University, Katahira, Aoba, Sendai 980, Japan \\ ${ }^{* *}$ Naka Works, Hitachi Ltd., Katsuta, Ibaraki 312, Japan
}

\begin{abstract}
The availability of several elements as a temperature indicator was studied. Suitable elements were Pd and $\mathrm{Ni}$. $\mathbf{P b}$ could be used only under the condition that $\mathrm{Pb}$ did not make an alloy with the matrix element. Sn was not useful because $\mathrm{Sn}$ in an alloy did work only in a very narrow dynamic range of temperature measurement. The correction factors of the experimental equations for each element were determined with air-acetylene and $\mathrm{N}_{2} \mathrm{O}$-acetylene flames. The factor obtained with the latter flame was found to be more accurate than that of the former. The effective vapor temperature in a graphite furnace was lower by several hundred degrees than the wall temperature when the factor obtained with the $\mathrm{N}_{2} \mathrm{O}$-acetylene flame was used. On the other hand, the factor obtained with the air-acetylene flame gave a vapor temperature in the furnace which was the same as that of the wall or slightly $\left(200^{\circ} \mathrm{C}\right)$ lower than it.
\end{abstract}

Keywords Effective vapor temperature, two-line method, palladium, nickel, lead, tin, graphite furnace, wall temperature

The wall temperature of graphite furnace is conventionally used as one of atomization temperatures of metals. In many cases, however, the temperatures of the sample itself and the atomic vapor being vaporized are different from the wall temperature. In order to make an analysis of the above phenomena, one must measure the temperature of the atomic vapor. In this paper, measurement of the atomic vapor temperature by atomic absorption spectrometry is described.

Several kinds of methods, such as the line reversal, the emission-absorption intensity ratio, and the slope of the Boltzmann plot, have been applied to measurements of the excitation temperature in flames, arc discharges and plasmas. $^{1-4}$ Since these methods were mostly based upon the phenomena of atomic emission, the line profile did not have to be considered, and only the integrated intensity was measured.

The two-line method for the temperature measurement by atomic absorption spectrometry has been investigated by L'vov. ${ }^{5}$, Chakrabarti et al. ${ }^{3}$, Siemer et al. ${ }^{6}$, van de Broek et al. ${ }^{7}$, Browner et al. ${ }^{8}$, Ide et al. ${ }^{9}$, and Kitagawa et al. ${ }^{10}$ These methods include the following conditions. The width of the emission line from the light source was much narrower than the absorption line width. The central wavelengths of the emission and the absorption lines exactly coincide with each other. However, since the ratio of the emission and the absorption line widths is about $1: 5$, both profiles could generally give an influence on the measurement of absorbance. In practice, the absorption line was recognized to shift to a longer wavelength. ${ }^{11}$ In such a case, it is almost impossible to determine the real absorbance.
It is necessary to observe profiles of both the emission and the absorption lines, and to estimate the lineoverlapping area.

The environment surrounding the atoms of interest in light sources such a hollow cathode lamp and an electrodeless discharge lamp is different from that in flames or in graphite furnaces. Accordingly, the difference in the species or concentrations of matrices causes discrepancies in the extent of the pressure effect (the Lorentz effect) on the atomic line. Owing to a big inequality of the pressure effect, the central wavelengths of the emission line from the light source and the absorption line do not coincide with each other, and both of the line profiles also become different. Yet, many studies on the two-line method of absorption have been based on assumptions that both central wavelengths are the same, and that the width of the emission line from the light source is much narrower than that of the absorption line. In the case of Zeeman atomic absorption spectrometry, it is more difficult to know the line profile, since absorption line splits in a complicated pattern depending upon isotopes.

Another way to adequately apply the two-absorption line method is to introduce an experimental correction factor $C_{\mathrm{f}}$ into an equation for the temperature calculation, which is determined by the two-absorption line method with the use of the air-acetylene flame. This method comes down to estimating a temperature of gas phase in the furnace by comparison with that of the airacetylene flame. The technical difficulties involved in this method are the following. The absorbance observed in the flame is dependent upon the profiles of 
contour lines of atomic density and the shapes of the beam from the light source at each cross section of the flame. It is difficult to define an adequate correction factor, because it is almost impossible to know where the light beam crosses over the contour lines of low or high atomic densities.

As a Zeeman atomic absorption spectrophotometer was used in this study, the line profiles were very complex and difficult to observe. Accordingly, the temperature calculation method by using the correction factor described above was applied in this study. The experimental equation used is given by Eq. (1), which was proposed by Reif et al.:1

$$
\ln \left(\frac{g_{\mathrm{m} 1} \cdot A_{\mathrm{n} 1-\mathrm{m} 1^{*}} \nu_{1}}{B\left(\mathrm{em}_{1}\right)}\right)-\ln \left(\frac{g_{\mathrm{m} 2} \cdot A_{\mathrm{n} 2 \rightarrow \mathrm{m} 2} \nu_{2}}{B\left(\mathrm{em}_{2}\right)}\right)=\frac{E_{\mathrm{m} 1}-E_{\mathrm{m} 2}}{k T_{\mathrm{eff}}}
$$

Here, $g$ is the degeneracy, $T_{\text {eff }}$ is the effective vapor temperature*, and $m_{1}$ and $m_{2}$ are the ground state or the lower slightly higher level above the ground state. $B\left(\mathrm{em}_{1}\right)$ and $B\left(\mathrm{em}_{2}\right)$ are the induced transition probabilities from excited states $\mathrm{n}_{1}$ and $\mathrm{n}_{2}$ to $\mathrm{m}_{1}$ and $\mathrm{m}_{2}$ levels, respectively. $A_{\mathrm{n} 1 \rightarrow \mathrm{m} 1}$ and $A_{\mathrm{n} 2 \rightarrow \mathrm{m} 2}$ are the spontaneous transition probabilities. $\nu$ is frequency. This equation can be simplified into Eq. (2):

$$
T_{\text {eff }}=\frac{E_{\mathrm{m} 2}-E_{\mathrm{m} 1}}{\ln \left(C_{\mathrm{f} .} \frac{\text { Abs. }\left(\mathrm{m}_{1} \rightarrow \mathrm{n}_{1}\right)}{\text { Abs. }\left(\mathrm{m}_{2} \rightarrow \mathrm{n}_{2}\right)}\right)} .
$$

Here, Abs. $\left(\mathrm{m}_{1} \rightarrow \mathrm{n}_{1}\right)$ or Abs. $\left(\mathrm{m}_{2} \rightarrow \mathrm{n}_{2}\right)$ corresponds to $B\left(\mathrm{em}_{1}\right)$ or $B\left(\mathrm{em}_{2}\right)^{1}$, and $C_{\mathrm{f}}$ is the correction factor. The intersectional area between the contour map of atomic density and the shape of the light beam is different in each flame and under each burning condition. In order to overcome this problem, two kinds of flames were chosen, and the following experimental procedures were established.

\section{Experimental}

\section{Procedure for determination of $C_{f}$ value}

1-1. To select suitable elements, absorbances of the two lines for several elements are measured with the airacetylene and $\mathrm{N}_{2} \mathrm{O}$-acetylene flames, and the correction factor $C_{\mathrm{f}}$ in Eq. (2) is calculated.

1-2. Comparing the $C_{\mathrm{f}}$ values obtained with the two different flames, and choosing the elements being yielded closer $C_{\mathrm{f}}$ values. This is necessary because errors occurring from the differences in the spatial distribution of atomic density in the flames should be eliminated.

* There are many expressions to this temperature as follows: excitation temp. ${ }^{9,10}$, gas phase temp. ${ }^{4}$, furnace atmosphere temp. ${ }^{2}$, effective gas phase temp. ${ }^{6}$, gas temp. ${ }^{7}$, effective vapor temp. ${ }^{3}$ and so forth are used.
2-1. Of several two-line pairs of thus selected elements, suitable two-line pairs giving a closer $C_{\mathrm{f}}$ value are nominated.

2-2. For the selected line pairs of the chosen elements, each $C_{\mathrm{f}}$ value is checked under fuel-lean and fuel-rich conditions of the flames, and the best line pair is chosen on the basis of the closest $C_{\mathrm{f}}$ value.

3. Choice of element as the reference temperature indicator. Using the best line pair, (a) temperatures on the fuel-lean and fuel-rich conditions are determined on the assumption that the temperature under the stoichiometric condition of the air-acetylene flame is $2600 \mathrm{~K}^{12}$ (b) The same measurement is made in the $\mathrm{N}_{2} \mathrm{O}$ acetylene flame. The temperature on the stoichiometric condition is assumed to be $3000 \mathrm{~K} .{ }^{8,13}$. The element and line pair selected are used as the reference temperature indicator.

4. Setting up the experimental equation for each element. $\quad C_{f}$ value for each element in each burning condition of each flame is determined with use of the reference temperature indicator. The $C_{\mathrm{f}}$ values obtained under the extremely fuel-lean and fuel-rich conditions which are not routinely used in atomic absorption measurements are eliminated. Finally, the experimental equations are derived for each element.

\section{Experimental measurement of $C_{f}$ values}

A Zeeman atomic absorption spectrophotometer with a flame assembly (Hitachi Z-6000) was used. This utilizes the inverse polarized Zeeman effect, in which a magnetic field is applied to the flame.

1. The $C_{\mathrm{f}}$ values for $\mathrm{Ni}, \mathrm{Pb}, \mathrm{Pd}$ and $\mathrm{Sn}$ were determined with the air-acetylene and $\mathrm{N}_{2} \mathrm{O}$-acetylene flames under different conditions from fuel-lean (the stoichiometric condition; which is at the left-most side of the measured points in Fig. 1) to fuel-rich conditions. The $C_{\mathrm{f}}$ values of $\mathrm{Ni}$ obtained with the air-acetylene and $\mathrm{N}_{2} \mathrm{O}$-acetylene flames are closer than the others. $\mathrm{Ni}$ was therefore chosen as the reference element for the temperature indicator.

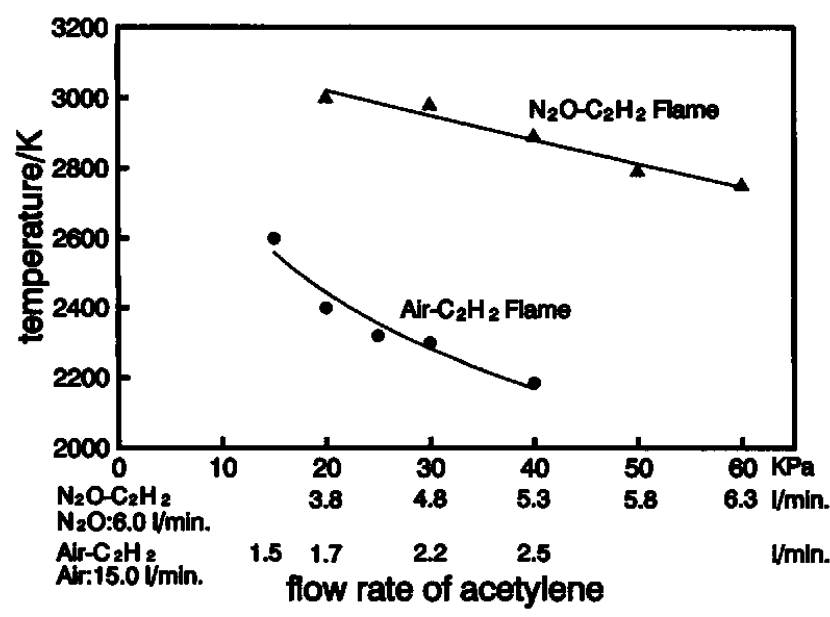

Fig. 1 Flame temperature. 
Table 1 Ratio of $C_{\mathrm{f}}$ values

\begin{tabular}{|c|c|c|c|c|}
\hline & $\begin{array}{c}229.0 \mathrm{~nm} \\
(0 \rightarrow)^{\mathrm{a}}\end{array}$ & $\begin{array}{c}323.3 \mathrm{~nm} \\
(0 \rightarrow)^{\mathrm{a}}\end{array}$ & $\begin{array}{c}337.0 \mathrm{~nm} \\
(0 \rightarrow)^{\mathrm{a}}\end{array}$ & $\begin{array}{c}233.7 \mathrm{~nm} \\
(0 \rightarrow)^{\mathrm{a}}\end{array}$ \\
\hline $\begin{array}{l}232.6 \mathrm{~nm} \\
(1332 \rightarrow)^{\mathrm{b}}\end{array}$ & 0.94 & 0.94 & 0.91 & 0.85 \\
\hline $\begin{array}{l}301.2 \mathrm{~nm} \\
(3410 \rightarrow)^{b}\end{array}$ & 1.42 & 1.41 & 1.37 & 1.28 \\
\hline $\begin{array}{l}338.1 \mathrm{~nm} \\
(3410 \rightarrow)^{b}\end{array}$ & 1.53 & 1.52 & 1.47 & 1.38 \\
\hline $\begin{array}{l}356.6 \mathrm{~nm} \\
(3410 \rightarrow)^{\mathrm{b}}\end{array}$ & 1.24 & 1.24 & 1.21 & 1.12 \\
\hline $\begin{array}{l}361.9 \mathrm{~nm} \\
(3410 \rightarrow)^{b}\end{array}$ & 1.44 & 1.43 & 1.39 & 1.30 \\
\hline
\end{tabular}

a. Transition from the ground state.

b. Transition from the non-ground state located at a higher energy level, and the number in the parentheses indicates the energy gap expressed in wavenumber $\left(\mathrm{cm}^{-1}\right)$.

2. The ratios of $C_{\mathrm{f}}$ values $\left(C_{\mathrm{f}}\right.$ in $\mathrm{N}_{2} \mathrm{O}$-acetylene/ $C_{\mathrm{f}}$ in air-acetylene) in each pair of Ni lines are listed in Table 1. It seems that the two-line pairs of $229.0 / 232.6 \mathrm{~nm}, 323.3$ / $232.6 \mathrm{~nm}$ and $337.0 / 232.6 \mathrm{~nm}$ are desirable, because the ratios are closer to unity. Unfortunately, as the atomic line of $232.6 \mathrm{~nm}$ has highly intense neighboring lines, these two-line pairs were not available because a wide slit was employed for measurements on a multi-channel atomic absorption spectrophotometer. This caused some spectral interference of the neighboring lines with the line at $232.6 \mathrm{~nm}$. Finally, the 233.7 and $356.6 \mathrm{~nm}$ were chosen as the optimum pair, and the experimental equation was derived.

3. The flame condition was altered by change of the flow rate of acetylene from 1.5 to $2.5 \mathrm{1} / \mathrm{min}$ in the airacetylene flame. The flow rate of air was kept at $15.0 \mathrm{l}$ / min throughout this experiment. We assumed that the flame temperature at an acetylene flow rate of $1.51 / \mathrm{min}$ is $2600 \mathrm{~K}$.

In the case of the $\mathrm{N}_{2} \mathrm{O}$-acetylene flame, the flame temperature was assumed to be $3000 \mathrm{~K}$ under the condition of $\mathrm{N}_{2} \mathrm{O}$ and acetylene flow rates of $6.01 / \mathrm{min}$ and $3.81 / \mathrm{min}$, respectively. The flame temperatures were measured under different flame conditions from fuel-lean to fuel-rich. The most conventional flame conditions are flow rates of acetylene between $4.81 / \mathrm{min}$ and $5.5 \mathrm{l} / \mathrm{min}$. The corresponding temperatures range from $2950 \mathrm{~K}$ to $2850 \mathrm{~K}$ (see Fig. 1). These values are in good agreement with the results obtained by Browner $e t$ $a l^{8}$ The temperature curve shown in Fig. 1 was used as the reference temperature, based on which the $C_{\mathrm{f}}$ value for each element was estimated.

4. The $C_{\mathrm{f}}$ values of the experimental equations for each element were obtained by changing the flame conditions. The flow rate of acetylene of the air-acetylene flame changed from 1.5 to $2.51 / \mathrm{min}$ and that of the $\mathrm{N}_{2} \mathrm{O}$ acetylene flame from 3.8 to $5.8 \mathrm{l} / \mathrm{min}$.

The line pair of $\mathrm{Ni} 233.7 / 356.6 \mathrm{~nm}$ did not have enough intensity for the multi-channel atomic absorption spectrophotometer. Therefore, this line pair was replaced by another pair: $323.3 / 356.7 \mathrm{~nm}$. Sample concentrations were adjusted to about $100 \mathrm{~g} / \mathrm{ml}$ so that the absorbance did not exceed $\mathbf{0 . 2 5}$.

\section{Measurement of effective vapor temperature in a graphite furnace}

A multi-channel atomic absorption spectrophotometer (Hitachi Z-9000) was used, because the simultaneous two-line measurement is feasible. This is also the inverse polarized Zeeman atomic absorption configuration in which the magnetic field crosses the graphite furnace. Light beams from two hollow cathode lamps for an element were focused in the central part of the furnace, and atomic absorptions were simultaneously measured at two different wavelengths.

Two kinds of atomization were studied. One was a slow atomization under the condition that the temperature was linearly rising from $1000^{\circ} \mathrm{C}$ to $3000^{\circ} \mathrm{C}$ during $20 \mathrm{~s}$, and the other was a rapid atomization controlled by an opto-pyrometric feedback circuit. Two kinds of sample conditions were applied; in the presence and in the absence of Pd matrix modifier. As the modifier for $\mathrm{Pd}$ measurement, $\mathrm{Ni}$ was used. Measurements of the wall temperature of the graphite furnace were made by an optical pyrometer, which was calibrated by measurement of the melting point of Mo. The gas flow of argon inside of the furnace was stopped when the atomization process started.

\section{Results and Discussion}

The flame temperatures estimated on different conditions are shown in Fig. 1; these were used as the reference temperatures. The flame temperature on the conditions used for routine atomic absorption measurements (a flow rate of acetylene of $1.7 \mathrm{l} / \mathrm{min}$ ) was found to be about $2400 \mathrm{~K}$. This value is close to those obtained by Browner et al. ${ }^{8}$ and Ide et al. ${ }^{9}$

The $C_{\mathrm{f}}$ values thus obtained for the test elements are listed in Table 2.

The $T_{\text {eff }}$ values calculated from Eq. (2) in the presence and absence of the matrix modifier on the slow atomization are plotted in Figs. $2 a$ and $2 b$, respectively.

Table 2 Correction factor $C_{\mathrm{f}}$

\begin{tabular}{cccc}
\hline & Line pair (nm) & Air- $\mathrm{C}_{2} \mathrm{H}_{2}$ & $\mathrm{~N}_{2} \mathrm{O}-\mathrm{C}_{2} \mathrm{H}_{2}$ \\
\hline $\mathrm{Ni}$ & $323.3 / 356.7$ & 3.41 & 4.29 \\
$\mathrm{~Pb}$ & $368.3 / 280.2$ & 1.44 & 1.89 \\
$\mathrm{Pd}$ & $276.3 / 340.5$ & 9.30 & 18.1 \\
$\mathrm{Sn}$ & $224.6 / 284.0$ & & 2.50 \\
\hline
\end{tabular}

Because the burning condition of the air-acetylene flame for the Sn measurement was so different from the others, the datum is not shown. 

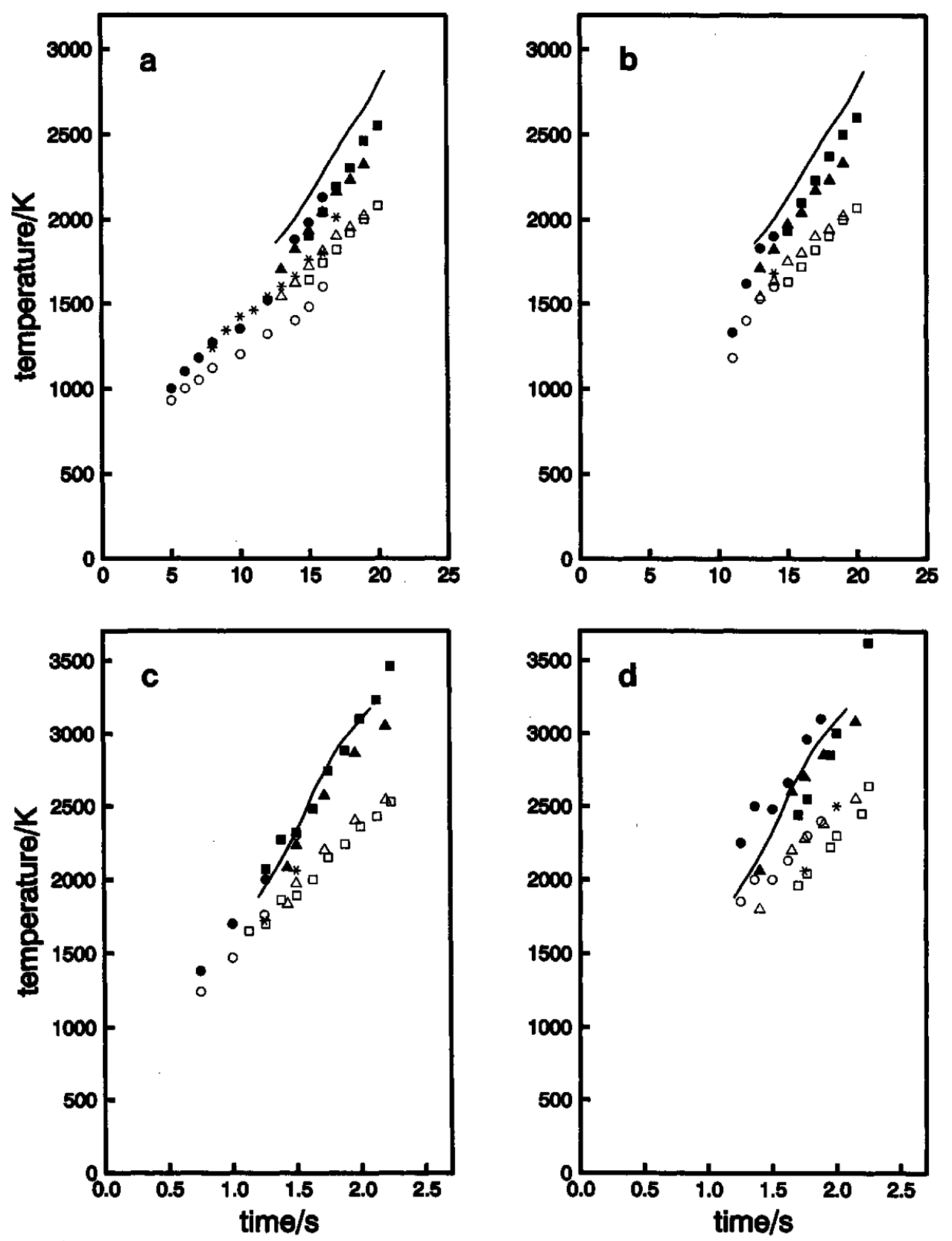

Fig. 2 Effective vapor temperature in graphite furnace. Solid line indicates wall temperature. $\Delta, \Delta, \mathrm{Ni}\left(C_{\mathrm{f}} 3.41\right.$ and 4.29$) ; \ominus, O, \mathrm{~Pb}\left(C_{\mathrm{f}} 1.44\right.$ and 1.89$) ; \square, \square, \operatorname{Pd}\left(C_{\mathrm{f}} 9.30\right.$ and 18.1); *, Sn $\left(C_{\mathrm{f}} 2.50\right)$. a, slow atomization in the absence of the matrix modifier; b, slow atomization in the presence of the matrix modifier; $c$, rapid atomization in the absence of the matrix modifier; $\mathrm{d}$, rapid atomization in the presence of matrix modifier.

Those obtained on the rapid atomization are presented in Figs. $2 \mathrm{c}$ and $2 \mathrm{~d}$, respectively. The summarized data are shown in Table 3.

\section{Ni as a temperature indicator}

Slow atomization. As seen from comparison between the results in Figs. $2 a$ and $2 b$, the effective vapor temperature was not influenced by the $P d$ matrix modifier. $T_{\text {eff }}$ estimated with $C_{\mathrm{f}}=3.41$ was lower than the wall temperature by about $300^{\circ} \mathrm{C}$. The value of this temperature difference is similar to that obtained by Chakrabarti et al. ${ }^{3}$

The $T_{\text {eff }}$ values obtained with $\mathrm{Pb}, \mathrm{Pd}$ and $\mathrm{Ni}$ are located on the same line. The $T_{\text {eff }}$ values with $C_{\mathrm{f}}=4.29$ are lower than the wall temperature by about $600^{\circ} \mathrm{C}$.

Rapid atomization. The $T_{\text {eff }}$ values estimated with $C_{\mathrm{f}}=3.41$ and 4.29 are lower than the wall temperature by ca. $100^{\circ} \mathrm{C}$ and $600^{\circ} \mathrm{C}$, respectively. This difference becomes larger at higher regions of the effective vapor temperature. $T_{\text {eff }}$ becomes higher by $200^{\circ} \mathrm{C}$ in the pres- 
Table 3 Working and dynamic ranges of the effective vapor temperature $(K)$ in graphite furnace

\begin{tabular}{|c|c|c|c|c|c|c|c|c|c|}
\hline & \multirow{3}{*}{$C_{\mathrm{f}}$} & \multicolumn{4}{|c|}{ Slow atomization } & \multicolumn{4}{|c|}{ Rapid atomization } \\
\hline & & \multicolumn{2}{|c|}{ No matrix modifier } & \multicolumn{2}{|c|}{ Matrix modifier } & \multicolumn{2}{|c|}{ No matrix modifier } & \multicolumn{2}{|c|}{ Matrix modifier } \\
\hline & & $\begin{array}{l}\text { Working } \\
\text { range }\end{array}$ & $\begin{array}{l}\text { Dynamic } \\
\text { range }\end{array}$ & $\begin{array}{l}\text { Working } \\
\text { range }\end{array}$ & $\begin{array}{c}\text { Dynamic } \\
\text { range }\end{array}$ & $\begin{array}{l}\text { Working } \\
\text { range }\end{array}$ & $\begin{array}{l}\text { Dynamic } \\
\text { range }\end{array}$ & $\begin{array}{l}\text { Working } \\
\text { range }\end{array}$ & $\begin{array}{c}\text { Dynamic } \\
\text { range }\end{array}$ \\
\hline $\mathrm{Ni}$ & $\begin{array}{l}3.41 \\
4.29\end{array}$ & $\begin{array}{l}1700-2400 \\
1400-2100\end{array}$ & $\begin{array}{l}700 \\
700\end{array}$ & $\begin{array}{l}1700-2400 \\
1400-2100\end{array}$ & $\begin{array}{l}700 \\
700\end{array}$ & $\begin{array}{l}2000-3100 \\
1900-2600\end{array}$ & $\begin{array}{r}1100 \\
700\end{array}$ & $\begin{array}{l}1900-3100 \\
1800-2600\end{array}$ & $\begin{array}{r}1200 \\
800\end{array}$ \\
\hline $\mathbf{P b}$ & $\begin{array}{l}1.44 \\
1.89\end{array}$ & $\begin{array}{r}1000-2200 \\
900-1600\end{array}$ & $\begin{array}{r}1200 \\
700\end{array}$ & $\begin{array}{r}1300-2000 \\
\cdot 1100-1600\end{array}$ & $\begin{array}{l}700 \\
500\end{array}$ & $\begin{array}{l}1300-2100 \\
1200-2300\end{array}$ & $\begin{array}{l}800 \\
900\end{array}$ & $\begin{array}{l}2200-3100 \\
1800-2600\end{array}$ & $\begin{array}{l}900 \\
800\end{array}$ \\
\hline Pd & $\begin{array}{l}9.30 \\
18.1\end{array}$ & $\begin{array}{l}1900-2600 \\
1600-2100\end{array}$ & $\begin{array}{l}700 \\
500\end{array}$ & $\begin{array}{l}1900-2600 \\
1600-2100\end{array}$ & $\begin{array}{l}700 \\
500\end{array}$ & $\begin{array}{l}2000-3400 \\
1600-2500\end{array}$ & $\begin{array}{r}1400 \\
900\end{array}$ & $\begin{array}{l}2400-3500 \\
1900-2600\end{array}$ & $\begin{array}{r}1100 \\
700\end{array}$ \\
\hline $\mathrm{Sn}$ & 2.50 & $1200-2000$ & 800 & $1600-1700$ & 100 & $1700-2000$ & 300 & $2000-2300$ & 300 \\
\hline
\end{tabular}

ence of the $\mathrm{Pd}$ matrix modifier than in its absence (see Figs. $2 \mathrm{c}$ and $2 \mathrm{~d}$ ). The $T_{\text {eff }}$ curve obtained with $\mathrm{Ni}$ in the absence of Pd matrix modifier, which is located under the $T_{\text {eff }}$ curve with $\mathbf{P d}$, shifts to a higher temperature region when the Pd matrix modifier exists. As a result, the $T_{\text {eff }}$ curve obtained with $\mathrm{Ni}$ slightly exceeded that with $\mathbf{P d}$. The appearance and residence times of the signal peak also become shorter.

\section{$P b$ as a temperature indicator}

Slow atomization. In the absence of the $\mathrm{Pd}$ matrix modifier, $T_{\text {eff }}$ estimated with $C_{\mathrm{f}}=1.44$ is lower by about $200^{\circ} \mathrm{C}$ than the wall temperature. This temperature difference is almost the same as that obtained by Chakrabarti et al. ${ }^{3}$ The dynamic range is wider, as seen in Table 3. $T_{\text {eff }}$ with $C_{\mathrm{f}}=1.89$ is lower by $500^{\circ} \mathrm{C}$ to $600^{\circ} \mathrm{C}$ than the wall temperature. The difference becomes larger as $T_{\text {eff }}$ becomes higher. In the presence of the matrix modifier, the temperature-rising becomes faster. The appearance and residence times of the signal peak also become shorter.

Rapid atomization. In the absence of the matrix modifier, the $T_{\text {eff }}$ curve obtained with $\mathrm{Pb}$ is in line with the $T_{\text {eff }}$ curve with $\mathrm{Pd}$, and almost the same as the wall temperature. The $T_{\text {eff }}$ curve with $C_{\mathrm{f}}=1.89$ is lower by about $200^{\circ} \mathrm{C}$ than the wall temperature. In the presence of the matrix modifier, the appearance time of the signal peak is delayed, and $T_{\text {eff }}$ is higher by about $200^{\circ} \mathrm{C}$ than that in the absence.

\section{Pd as a temperature indicator}

Slow atomization. In the absence of the $\mathrm{Ni}$ matrix modifier, $T_{\text {eff }}$ estimated with $C_{\mathrm{f}}=9.30$ is lower by about $300^{\circ} \mathrm{C}$ than the wall temperature. The rising curve of $T_{\text {eff }}$ shows almost the same behavior as that of the wall temperature, and shows the same trend as well as that obtained with Ni. $T_{\text {eff }}$ with $C_{\mathrm{f}}=18.1$ is lower by about $700^{\circ} \mathrm{C}$ than the wall temperature, and also $100^{\circ} \mathrm{C}$ lower than the $T_{\text {eff }}$ curve obtained with Ni. Addition of the Ni matrix modifier had little effect on this $T_{\text {eff. }}$.

Rapid atomization. In the absence of the matrix modifier, $T_{\text {eff }}$ with $C_{\mathrm{f}}=9.30$ is almost the same as the wall temperature. The maximum value of $T_{\text {eff }}$ exceeds that of the wall temperature and is $200^{\circ} \mathrm{C}$ higher than the $T_{\text {eff }}$ curve obtained with $\mathrm{Ni}$. $T_{\text {eff }}$ with $C_{\mathrm{f}}=18.1$ was about $200^{\circ} \mathrm{C}$ lower than the wall temperature in the lower $T_{\text {eff }}$ region. This difference becomes larger and reaches $700^{\circ} \mathrm{C}$ in the higher $T_{\text {eff }}$ region. In the presence of the matrix modifier, the appearance time of the signal peak is delayed, and the $T_{\text {eff }}$ curve has a steep slope. However, the maximum temperatures of $T_{\text {eff }}$ are the same under both conditions.

\section{Sn as a temperature indicator}

Slow atomization. In the absence of the matrix modifier, the working range of the effective vapor temperature is from $1200 \mathrm{~K}$ through $2000 \mathrm{~K}$, which is a wider dynamic range $\left(800^{\circ} \mathrm{C}\right)$ than that of the others. On the other hand, the signal peak exists for a short residence time or within a narrow temperature range of about $100^{\circ} \mathrm{C}$ in the presence of the matrix modifier.

Rapid atomization. The residence time of the signal peak is limited within a short period, which corresponded to the effective vapor temperature range of about $300^{\circ} \mathrm{C}$. In the presence of the matrix modifier, the peak appearance time is delayed, and $T_{\text {eff }}$ becomes higher. However, the dynamic range of the effective vapor temperature is too narrow, i.e. about $300^{\circ} \mathrm{C}$, regardless of the presence or absence of the matrix modifier.

The phenomena described above are summarized as follows.

On slow atomization: the effective vapor temperatures obtained with $\mathrm{Pd}$ and $\mathrm{Ni}$ were not much influenced by addition of the matrix modifier. Appearance of $\mathrm{Pb}$ signal was delayed by addition of the modifier. The Sn signal became very sharp in the presence of the matrix modifier. The $T_{\text {eff }}$ 's obtained with $\mathrm{Pb}, \mathrm{Ni}$ and $\mathrm{Pd}$ were lower by about $200^{\circ} \mathrm{C}$ than the wall temperature, and they are located on the same curve on the time scale when the $C_{\mathrm{f}}$ values were corrected by the results obtained with the air-acetylene flame.

On rapid atomization: every effective vapor temperature was influenced by the presence of the matrix modifier. The appearance of the $\mathrm{Pd}, \mathrm{Pb}$ and $\mathrm{Sn}$ signals were delayed by addition of the modifier. In the 
presence of the matrix modifier, the effective vapor temperatures obtained with $\mathrm{Pb}$ and $\mathrm{Sn}$ became higher than those in their absence.

The width and length of fire tail of the air-acetylene flame were narrower and shorter than those of the $\mathrm{N}_{2} \mathrm{O}$ acetylene flame, respectively. Consequently, the contour lines in the atomic density map densely existed. Therefore, it was not certain that the light beam from the hollow cathode lamp passed only through the high density area of atomic vapor in the air-acetylene flame. This problem was also suggested by the evidence that the $T_{\text {eff }}$ values obtained with the $\mathrm{N}_{2} \mathrm{O}$-acetylene flame were lower than those with the air-acetylene flame. $T_{\text {eff }}$ obtained with $\mathrm{Sn}$ by making use of the $\mathrm{N}_{2} \mathrm{O}$-acetylene flame in the presence of the Pd modifier was $1664 \mathrm{~K}$ which was close to the melting temperatures of $\mathrm{Pd}_{3} \mathrm{Sn}$ $(1599 \mathrm{~K})$ and $\mathrm{Pd}_{2} \mathrm{Sn}$ alloy $(1560 \mathrm{~K}){ }^{14}$ Therefore, these results suggest that the $\mathrm{N}_{2} \mathrm{O}$-acetylene flame is preferable for the determination of the $C_{\mathrm{f}}$ value.

Another problem is as follows. The wall temperature was measured in the middle part of the furnace, while the effective vapor temperature obtained by the two-line method includes that in the central part, but also includes that in the low temperature regions at both ends of the furnace. In other words, the area where the wall temperature was measured was not identical with the area where the effective vapor temperature was measured. It is necessary to correct the effective vapor temperature in conjunction with the longitudinal distribution. The effective temperature in the middle part of the furnace might be slightly higher than that observed in this experiment.

$\mathrm{Pd}$ and Ni were found to be widely used as temperature indicators. It should be noted that, even under severe conditions, or rapid atomization, the effective vapor temperature obtained with Pd was less influenced by the presence of a matrix modifier than that with Ni. Sn is not preferred, because its dynamic range was too narrow.
This is probably due to the formation of its alloy with the matrix element.

The authors would thank Messrs. K. Harada and A. Yonetani at Hitachi Ltd. for their considerate assistance.

\section{References}

1. I. G. Reif, V. A. Fassel and R. N. Kniseley, Spectrochim. Acta, 28B, 105 (1973).

2. R. S. Koirtyohann, R. C. Giddign and H. E. Taylor, Spectrochim. Acta, 39B, 407 (1984).

3. C. L. Chakrabarti, S. Wu, R. Karwowska, J. T. Rogers, L. Haley, P. C. Bertels and R. Dick, Spectrochim. Acta, 39B, 415 (1984).

4. B. Welz, M. Sperling, G. Schlemmer, N. Wenzel and G. Marowsky, Spectrochim. Acta, 43B, 1187 (1988).

5. B. V. L'vov, J. Quant. Spectrosc. Radiat. Transfer, 12, 651 (1972).

6. D. D. Siemer and W. Frech, Spectrochim. Acta, 39B, 261 (1984).

7. W. M. G. T. van den Broek, L. de Galan, J. P. Matousek and E. J. Czobik, Anal. Chim. Acta, 100, 121 (1978).

8. R. F. Browner and J. D. Winefordner, Anal. Chem., 44, 247 (1972).

9. Y. Ide, M. Yanagisawa, K. Kitagawa and T. Takeuchi, Bunko Kenkyu, 24, 144 (1975).

10. K. Kitagawa, Y. Ide and T. Takeuchi, Anal. Chim. Acta, 113, 21 (1980).

11. K. Yasuda, Anal. Chem., 38, 592 (1966).

12. R. Mavrodineanu and H. Boiteux, "Flame Spectroscopy", pp. 22 - 26, Wiley, New York, 1965.

13. I. G. Reif, V. A. Fassel and R. N. Kniseley, Vol. 2, p. 317, CSI XVI at Heidelberg, 1971.

14. R. P. Elliott, "Constitution of Binary Alloys", 1st Supplement, p. 733, McGraw Hill, New York, 1965.

(Received March 28, 1991)

(Accepted June 13, 1991) 